\title{
The Unclassical Design of Jonson's Comedy
}

\author{
RENU JUNEJA
}

Thirty years ago, Freda Townsend warned critics of Ben Jonson that a demand for the single, well-knit, coherent intrigue of Plautine comedy or even the double intrigue of a Terentian comedy was grossly unfair to a playwright who shared his fellow dramatists' taste for multiplicity of action. Recent criticism, however, still faintly damns the various plot actions in Dryden's term "copiousness," and seeks unity in theme and inspiration. ${ }^{1}$ The last decades have been kinder to Shakespeare. Research into earlier English staging has brought forth a spirited defense of Shakespeare's intrusions within his consequential plot structures as well as a much wider acceptance of his manipulation of temporal and spatial sequences. If an analogous appreciation of Jonson's plot structures is to be achieved, Jonsonian critics must also remind themselves that whatever Jonson the classicist might theorize, his practice was rooted in the techniques and traditions of Elizabethan drama. ${ }^{2}$

Research has contributed significantly to structural criticism of Shakespeare and all Elizabethan drama, for not only has it uncovered roots in late medieval drama but it has forged the link between the drama and the visual arts. ${ }^{3}$ An important development in English narrative art was that of compacting several episodes, unrelated causally, into one structure. Thus, fourteenth-century artists of full-page illuminations in Psalters might arrange scenes horizontally and vertically in patterns that formed a single architectural unit. When viewing, for instance, the six scenes from the life of Christ in the Psalter of Robert de Lisle, the eye moves from one unit of time and space to another just as the eyes of medieval audiences took in more than one locale and more than one episode in street shows. Neither time, place, nor incident was necessarily consequential. The staging of medieval street shows and later miracle plays was processional, merely sequential; each unit might stand on its own.

Elizabethan drama inherited the ambiguity in time which allowed double-time, even triple-time; it retained the neutral setting which served several locales; it salvaged processional qualities which interfered with 
the strict causality of classical plots. From traditional art and the tableaux vivants came the practice of including emblematic scenes, scenes which might interrupt the narrative flow to display visually and so vividly character, emotion, or pageantry. Shakespeare, time after time, juxtaposes spatially organized, back-to-back scenes so that his audience moves not consequentially but pictorially from Brutus and Portia to Caesar and Calpurnia, from an unrepentant Claudius at prayer to a consciencestricken Gertrude bending under Hamlet's indictment. For Shakespeare, such tableaux were insertions into consequential patterns; he brought in "causality before and after his pictures, so that there is a sequence in character." 4 Jonson, however, adopted spatially organized, sequential scenes as the exclusive basis for structuring his plays. Although at times he employed techniques of Roman comedy, as in the narrative order in Every Man In His Humour, the subordination of minor actions to a dominant intrigue in Epicoene, The Alchemist, and Volpone, his artistic inclination was toward juxtaposition and co-emphasis. These qualities pleased in Renaissance paintings. How was Jonson to achieve a comparable pleasure in the theatre, and how was he to counter the weaknesses in episodic, sequential drama which ordinarily lacks the organic dynamism, the proportion, the climactic emphasis of Latinate comedy?

Jonson turned to music. The concepts and techniques of late Renaissance music served to unify the multiple actions of his plots. Although some critics have made useful, incidental comparisons to dance and music rhythms, there is need to relate the total structure of a Jonson play to musical forms of the age: specifically to explore what aspects of his plot structure can be correlated with musical forms. ${ }^{5}$ Of course, we must be careful that the analogy does not become too literal and thereby lose its instructive value.

Polyphonic music comes to its own in the Elizabethan age, and it is to the sacred motets and the secular, more popular, madrigals that we must go for an understanding of the special rhythmic character of Jonson's plots. Both the motet and the madrigal used three or more voices and both were fugal and contrapuntal in nature. The voices entered the piece successively and not simultaneously. The madrigal in this sense was essentially episodic (one point of imitation was based on less than one line of text). Also, not only was there a succession of entries, a new voice could enter even while the earlier voice was finishing a phrase. Even as one attempted to follow the treble through its melodic mazes, one would become aware that the tenor had joined and was harmonizing several pitches lower; even as one followed the tenor's progress, the cantus secundus would pick up the strain, and so on. Consequently, no clear sense of cadence could be achieved till the end of the composition. Even more important, the lines of melody retained their independence 


\section{6/ Renaissance and Reformation}

without sacrificing rhythmic harmony, and this was achieved through repetition of words and strains as well as through rhythmic contrasts among voices.

If such a concept of form is adapted to dramaturgy, the result is a plot structure startlingly different from the causal, dominant intrigue pattern of the classical comedy. For instance, there is little room for the medias res pattern of crisis drama. Indeed, if we pause for a moment and systematically link together the Renaissance aesthetic assumptions as they can be derived from the visual arts and music, we can offer for Jonson a concept of design radically different from the classical. The structure of the plots is spatial and not temporal;i.e., very often scenes do not advance the narrative flow but allow for characters to come and attitudinize in front of us. Amplification and not causality provides the principle of development. The various segments of action retain their autonomy and are patterned not through subordination, but through coordination. The scenes, which often have the emblematic quality of "living tableaux," proceed in a sequential manner. The plot, instead of being hierarchically arranged and gathering to a single point of crisis, is likely to have several moments of explosion and resolution because different strands of intrigue have different rhythmic movements which begin and end in different intervals. These polyphonies of action achieve their coordination through fugal counterpoints, and through repetitions, echoes (imitations), and variations. Even when there is subordination (as in The Alchemist, Epicoene, and Volpone), it is unlike that of New Comedy with its one focal intrigue, and is more like that of the contrapuntally accompanied Elizabethan solo-song where the upper voices generally carried the syllabic setting while the lower voices, noticeably less melodic, wove an amorphous polyphonic texture below the tune.

Though Jonson is not unique in adapting techniques from visual arts and musical form to drama, his contemporaries (Shakespeare in particular) employed these techniques merely as added dimensions to essentially narrative plots. Because he pays less attention to causality and narrative flow, choosing instead a heavily episodic, sequential structure, Jonson has greater need to rely on a structural harmony based on music. His uniqueness lies in the shift of balance away from story-telling to integration of autonomous pieces of actions through structural elaboration. In a sense, then, the outward form of Jonson's plays differs from that of contemporary plays; perhaps he substituted the classical five-act structure to compensate for the lack of a narrative framework.

I have chosen Every Man Out of His Humour, Cynthia's Revels, and Bartholomew Fair to reveal the Jonsonian design. Two are early experiments while one belongs among his four masterpieces. They have been chosen not because they are the happiest examples of Jonson's method, 
but because they are the most extreme, making it easier for the critic to isolate distinctive elements. There are enough structural similarities, however, in all of Jonson's plays to suggest that even his more "regular" comedies would benefit from a similar analysis. The three chosen plays are alike in their plenitude of characters (each play has twenty or more speaking roles) and their bewildering multitude of actions. Here Jonson makes little attempt to lock in different strands of action, and so does not create the illusion of a complex, well-knit structure made up of intertwined intrigues so often praised in plays like The Alchemist and Epicoene. Nor is there a common action in which a considerable group of characters takes part; for while the Fair may be said to provide a common business in Bartholomew Fair, it lacks the cohesive and compelling centrifugal force of intrigues spun by central characters in Jonson's other plays. It may well be that Jonson's greatest successes tended to come when he infused at least an illusion of a conventional narrative line into his plots; the enormous power of Bartholomew Fair, however, indicates that the method could succeed even at the most extreme, in a play which offers little of the excitement of an intrigue propelled to a breathless resolution.

The various actions in Every Man Out remain separate, and begin, expand, and resolve in a sequential pattern. Macilente's action begins at the opening of the play with his envy of Sogliardo, reaches its climax when he poisons Puntarvolo's dog out of inexplicable malice, and resolves itself at the end of the play when he finds himself drained of all envy. Similarly, we are introduced to Sordido in the third scene of the first act. We see him express the extremity of his miserly nature in Act III, scene vii, a scene which constitutes the climax of his folly, and we see the resolution of his wretched humour in the same scene when he is cut down before he can successfully hang himself. The arrival of new characters signals the beginning of several independent actions. Thus the action involving Sogliardo begins in Act I, scene ii, and that involving Funguso in Act II, scene iii. One particular action may be accented at one moment, and may recede at another, to come forward again subsequently. Our acquaintance with Brisk begins in the second act, and Jonson allows us to expand our knowledge of him in a scene devoted largely to him (II, vi). Then he fades for a while as Jonson brings in three new characters (Shift, Clove, and Orange) in the third act.

This little action, call it "aria," devoted to Shift, Clove, and Orange illustrates most perfectly Jonson's technique of introducing independent actions in the middle of a plot in a manner which resembles the entry of new voices in the polyphonic madrigal. The previous scene, where Deliro has introduced Macilente to Brisk as a scholar, prepares us for Clove and Orange, the two coxcombs who pretend at scholarship. 
Macilente is at least a true scholar, though scholarship has lost its value by being perverted by his envy. Clove and Orange can only bandy words they cannot understand and are quickly silenced. Macilente's silence, not so easily forthcoming, presents, when it comes, both an ironic parallel and a paradoxical contrast. For Macilente is ultimately choked by his own words, silenced not by another's eloquence, but by his own. Similarly, Shift, the cowardly pimp, both contrasts and repeats the actions of Puntarvolo. Even as Puntarvolo parodies the behaviour of a true knight by his mechanical posturing, so Shift parodies a gentleman's accomplishments by posturing with his sword. Both indulge in meaningless shows, but at least Puntarvolo has some claims to being a gentleman of breeding whereas Shift has none. Thus Jonson gives parallels and contrasts in character a structural relevance, and makes succeeding actions amplify the preceding ones through a kind of incremental repetition. By the time the third act ends, the little action of Clove, Shift, and Orange has resolved itself because of their failure to impress Buffone and Puntarvolo, and the stage is left free for the other actions to come forward.

Similarly, the choric comments form an independent thread of action which begins with Asper introducing Cordatus and Mitis to the play and ends with Asper rejoining them - with the play now fully and neatly explained by Cordatus for both the audience and Mitis. The Grex, choral in function, reveals a structural peculiarity that Jonson perhaps learned from the art of medieval painting. We see a central core of action framed, as it were, with various layers of perspective provided by observers and commentators. In the opening scene of Every Man Out, we find Buffone, a minor observer, completely involved in his interchange with Sogliardo. Macilente, also present on the stage, stands a degree removed from the action, while the Grex stands completely on the edge of it.

Even when there are no choral commentators, there are always observers who, even though they participate in the action, watch the proceedings of the other characters with a relatively dispassionate eye. In Bartholomew Fair, when Quarlous and Winwife announce that they will visit the Fair specifically to watch fools commit their follies, we are prepared by Jonson to look for concentric, centrifugally expanding layers of awareness. In Act II, scene vi, this sense of observing layers within layers is particularly intensified: the Bartholomew birds closely hawk their victims; they in turn are under the scrutiny of Overdo, who is searching for enormities; and all of them are carefully observed by Winwife and Quarlous, who alone perceive what is happening. In Cynthia's Revels, Cupid and Mercury function as commentators, and often thus frame the scenes in which they appear. The mythological 
backdrop and the various songs which evoke this mythology provide but another kind of structural framing in this play. The mythological opening with Echo's song of Narcissus and the mythological close where perfect harmony is finally achieved in Cynthia's ideal court frame the antics of the poor mortals, and thus lend meaning and structure to the otherwise episodic scenes. In their games and encounters and their mock court, these lovers act out both the parody of the Narcissus theme and the related theme of social and cosmic harmony envisaged in Cynthia and her court.

Jonson also often spotlights a particular action or a character or a group of characters by deliberately confining them in space, and though such scenes are usually riotously comic, they often retain a symbolic quality, especially if they were acted in the specifically designated discovery space. ${ }^{6}$ The tableau of Volpone's hymn to gold, the picture of him framed by the stretcher posts as he is carried into the court simulating death, the little show of the confining of Sir Pol in a tortoise shell all these are scenes where human actions gain a heightened significance by being marked off in space. In Epicoene, La Foole and Jack Daw lose their swords, and symbolically their manhood in the privy. From the privy, the most private space of the house, comes the voice of Dapper in The Alchemist, finally and unequivocally exposing Face to his master. The debtors' prison in Every Man Out is another scene so framed in symbolic space. In Bartholomew Fair, Ursula's booth functions as a symbolic centre of that world of misrule. Indeed, as Kaplan has pointed out, the three prominent stage properties (the pig booth, the stocks, and the puppet stand) are visual emblems for the three emblematically central areas of experience - appetite, law and art. ${ }^{7}$ Significantly again, the transformation of Win and Dame Overdo to "birds o' the game" takes place after their visit to the privy. The confinement of the three figures of authority in stocks has both symbolic and delightfully scatological overtones (they are impotent because now "framed" in wooden garters).

Shakespearean critics have often noted the presence of mirror scenes in his plays. When the Gardener instructs his assistant in Richard II, or the Old Man recounts to Ross the horrors of the night gone by in Macbeth, or when Lear rages on the heath, for a moment the dimension of time is suspended and we see the characters play out a heavily symbolic drama against a backdrop of timelessness. ${ }^{8}$ Scenes with similar dimensions exist in Jonson, though perhaps not so starkly etched out as Shakespeare's who deliberately highlights them by deferring a causally dynamic action. Since such a narrative dimension seldom exists for Jonson, he can only spotlight his mirror scenes by adding a new spatial dimension. This, as I have suggested, he does through framing - either 
by confining the characters in a marked area of space or by making several characters look on at a core of action, thus demarking distinguishable layers of perspective.

Jonsonian critics, even when they show awareness of the magnetic thrust of space as against that of time, usually confuse the issue by bringing anachronistic expectations from the narrative intrigue comedy. Thus Wallace Bacon, who talks of magnetic centres, laments that Jonson disperses intensity by providing more than one centre of attraction. To speak thus is to think in mental sets of one climax and one dénouement. Jonson's plays have several independent actions and also often more than one magnetic pole. These poles may be groups of characters or areas of space, and a double pull may sometimes generate a characteristically Jonsonian tension. The last scene in Cynthia's Revels has obviously symmetrical and emblematic dimensions derived from medieval painting. Cynthia on her throne presents the focal point around whom the several figures are arranged symmetrically, and around whom they exit or stand in balanced pairs. The play, however, has more than one centre - there is also the well of selfishness of the earlier part of the play. If the visual focal point of one centre is Cynthia in her chair of state, that of the other is Moria as she sits enthroned and canopied in her mock court. These two frame the courtiers in the inbetween place, and as they attract or repulse the characters, they generate a sense of direction in the play. Indeed, the movement toward one or the other centre determines both the thematic line and the plot line.

One of Jonson's technical problems must have been how to produce the illusion of dramatic movement in a spatially organized plot. Sometimes, as we have seen in Cynthia's Revels, the dynamics of space can provide its own logic of movement. Jonson also lends progression to his plots by repeatedly initiating new actions. We have seen how in Every Man Out the exposition is fugal and the action sequential. This is equally true of Cynthia's Revels, which opens with a quick, dramatic Induction, with the three boy actors fighting with each other for the right to speak the prologue. Once the play moves into the world of myth and allegory, however, the pace does slow down. The characters are introduced one by one, and the orchestration builds up more slowly and elaborately than in Every Man Out, but nevertheless musically. The play may seem more static in a reading than it would be in an actual performance, where the descriptive, expository portraits painted by Cupid and Mercury would merely sharpen our response to the acting out of follies by the courtiers. The first act is taken up by the gradual introduction of the different characters in small scenes consisting of relatively small gatherings (never more than three at a time till the fifth scene), where people display their individual follies. In the following acts the characters 
gather in larger groups, interweave, and move apart. Jonson maintains a clear design by effectively pairing off the characters - Cupid and Mercury, Crites and Arete, Amorphous and Asotus, Hedon and Anaides. The pairing is varied when the women appear, because each gallant now has a mistress who complements and supplements his folly. In the first four acts, as the characters assemble and group themselves, there emerges a strong sense of a "repetitive scenic pattern." 9 We see this kind of structural orchestration especially in the scenes where the gallants play games (games in which each one comes forward to say his piece and retires), as well as in the scenes where they practise and tutor each other in the art of repartee. The dance-like movements of the participants in the game of buzz and dor find their climactic fulfillment in the two masques, which end with the final musical recantation of the palinode.

Such a structural and thematic orchestration begins, in fact, with Echo's song, which is a kind of recantation and a comment on her past life, and ends with another song referring to "weeping eyes" and "sweeter waters." Significantly, the first song is a canzonet and calls for three voices. Mercury summons voices out of air to aid Echo, and the polyphonic song proceeds through repetitions and variations of words like "drop," "slow," "tears." The other songs in the play very deliberately contrast with Echo's song even as they reveal character by functioning as a comment on the singer. For instance, the songs in III. iii and IV.i, the one patterned on the disordered speech of the mock courtiers and the other a sentimental love song, contrast both in tone and line lengths with the sorrowing fountain song. The two masques further this orchestration, and the final palinode, where the courtiers exit in singing pairs, provides a choral finish by drawing together the different threads of the plot. As the Jonsonian audience left with music ringing in its ears, it would surely have been aware of the analogies to musical form in this play where actions of characters are knit together in musical patterns.

The deliberate pairings in Cynthia's Revels are a way of coordinating the various characters and cleverly orchestrating independent actions. Similarly, in Every Man Out, the characters involved in the various actions do not always stand isolated. Groups form within them and they shift apart to come together again. Macilente and Buffone are everywhere, moving between different actions, helping them forward, and bringing them to a conclusion. These two, however, are different from the witty slaves of intrigue comedy (or even Brainworm in Jonson's Every Man In His Humour) in that they are not merely agents; they too have their lines of action, attendant on others, but independent.

As the stage gets increasingly crowded in Every Man Out, and the 
characters move around each other, some of the actions are bound to reach a common resolution. The exposure of Shift leads to Sogliardo's deflation, just as the discovery of Fallace and Brisk in the prison (their exposure) causes Deliro to return to his senses. This kind of interconnection Jonson attempts in order to achieve structural economy. It is, however, impossible to see in this any complex working out of cause and effect. The coherence is that of a musical movement where two people or two voices come together for a moment to orchestrate a sequence and then move apart to join other voices. For instance, in the scene at St. Paul's aisle (III.iv) a great number of characters come together, exchange remarks, and then move off to form new groups, a new pattern of voices. Each character gets his moment of spotlight when his particular movement comes to a climax, is resolved, dies away giving place to another. Thus in Every Man Out, the exposure comes in a graduated crescendo as Sordido, Sogliardo, Shift, Saviolina, Puntarvolo, Fungoso, Carlo, Brisk, Fallace, and Macilente each have their moment of reckoning and discomfort; these moments structurally duplicate each other but at the same time thematically and musically vary it.

Unlike Every Man Out, where the actions arrive at individual climaxes and are resolved one after another in a steady crescendo of exposures, in Cynthia's Revels, the actions, though individually introduced, soon merge into group activity, and the false courtiers all share their moment of exposure. The actions involving Cupid, Mercury, and Crites remain separate, but they too reach their resolution at the same time - Cupid is banished from the court, Mercury entreated to stay, and Crites, who is asked to pass judgement on the false courtiers, arrives at a new, mature insight about vice. With all the notes of discordance removed or suppressed, the mythical, allegorical, and the real stand harmoniously juxtaposed in Cynthia's ideal court - a court which duplicates the harmony of the cosmos.

The structural similarities between the opening of Bartholomew Fair and the plays considered so far are obvious. The analogy of the polyphonic madrigal still holds, for the characters assemble on the stage successively, till at the end of the first act, all the major characters have gathered (with the exception of Overdo, who is mentioned at the close of the act, and who is already at the Fair), and are ready to move to the Fair. Similarly, once at the Fair, the denizens appear one by one, either as they emerge from the booth or converge toward it, and we get ready for the mingling of the outsiders with the natives. Significantly, the two observers (Winwife and Quarlous) who maintain a relative distance from the activities of the Fair are the first to appear, allowing Jonson the possibility of a slow and gradual expansion of the various actions and preventing a sudden, chaotic intermingling which could blur the distinctions between the separate plots. 
Once at the Fair, the gulling of the different characters is again successive, and the climaxes arrive in a sequential manner. Cokes, the first of the victims to arrive, is the first to precipitate a crisis when he loses his purses in the third act, as he is also the first to achieve resolution through exposure when he finds his true place among the puppets. Of the three guardians, Overdo is the first to get himself into trouble (he gets himself beaten by Wasp in II.v), and he is the first to be put into the stocks. In the meanwhile, Busy has begun to cause disturbance (he overthrows the gingerbread stall in II.vi), and is arrested by the officers at the end of the scene. Wasp achieves his peak of irascibility in Act IV, scene vi, to be arrested and put into the stocks. In a kind of reverse motion, Wasp is the first one to be deflated; he is shut up by Cokes in Act $\mathrm{V}$, scene iv, and realizes that he must learn to correct himself before he corrects others. Busy is the next to be overcome in Act V, scene vi; he is deflated and conquered in his disputation with the puppet Dionysus. Overdo is the last to arrive at a realization. In the last scene, silenced by the debauched state of his wife, he is forced to recognize that he too is "Adam, flesh and blood."

For all the apparent confusion and the multiplicity of action in Bartholomew Fair, Jonson retains a firm control on the plot movements, maintaining a musical symmetry through all the complicated involutions. Richard Levin has shown how the visitors to the Fair belong to distinct groups which are established even before the action proper begins. There are definite parallels among these groups, and the people in one group have their counterpart in the other. (Levin sees them as almost symmetrical, each having its self-appointed leader, its little wit, and its eligible woman.) The structure of the play, as Levin sees it, is determined by what happens to these groups when they enter the Fair:

\begin{abstract}
At first these groups preserve their distinct identities, remaining intact and isolated from each other; but as they become caught up in the fair, they gradually disintegrate until every person is on his own, and at the same time the contacts between groups gradually increase, contributing to this breakdown and eventually producing a rearrangement of the two main parties. ${ }^{10}$
\end{abstract}

Levin's corollary arising from this analysis, the most interesting from the point of view of my musical metaphor, is that each visitor's progress in the Fair becomes a kind of plot in itself. Thus, in the careers of the several visitors, we can discern an independent line of action which has its own beginning, climax, and resolution, even while the destinies of these characters are a part of a larger pattern and of a shared resolution.

The final act of the play is particularly a tectonic masterpiece. The gradual exposures parallel the gradual introduction of the first act, giving to the play a unique harmonic quality. Act $\mathrm{V}$ begins at the peak 
of chaos with Leatherhead and Filcher discussing the play's greatest enormity - the puppet show. The cacophonous puppet show is a structural and thematic variation of the harangue among the three figures of authority in the stocks and the vapours combat. In Act V, scene ii, the Justice is still disguised as a porter and Quarlous has donned the habit of a madman. In Act V, scene iii, Cokes enters, shorn not only of his money, but also of his outer clothing, and chased by urchins. In the fourth scene, Win and Dame Overdo are ushered in, inebriated and unlovely, as prostitutes. As the act proceeds we have repeated uncoverings: Purecraft discovers herself in Act V, scene v; and Quarlous throws off his disguise in Act V, scene vi. Overdo's presumptuous and wrongheaded passing of judgement is followed by Quarlous' legitimate passing of judgement, and the play closes with a movement away from the Fair, as it had opened with a movement toward the Fair.

The episodic structure of Jonson's plays lends itself to an expansion through plenitude or amplification, where, one after another, the satiric targets are drawn in. In such a case, the return movement is also most naturally sequential - something like the gradual diminuendo or crescendo of a musical composition where each voice repeats a phrase more faintly or strongly until the melody comes to rest. This rhythmic method of plotting explains a curious feature of Jonsonian comedy. Though Jonson often gives us a composite resolution (not the same as a single resolution) in plays like Cynthia's Revels, Every Man in His Humour, Epicoene, and Bartholomew Fair, he is equally likely to dissolve an action independently so that a particular character or a group of characters will disappear much before the fifth act. As we have seen, Sordido in Every Man Out has finished his little drama by the end of the third act. In Poetaster, the Ovid plot reaches its climax of folly in the banquet scene (IV.iv) and its resolution at the end of Act IV. The disappearance of Ovid in Act IV can be seen as a structural flaw only if we expect from Jonson a Terentian delayed completion of a single, well-defined goal. But in Jonson there is seldom one structural focus which persists throughout the play.

A typical Jonsonian play is made up of several theatrical segments which are harmonized through musical coordination even as they retain their autonomous character. Indeed, we may even say that with each successive introduction of a character begins a different action which subsides only when that particular character finally disappears from the stage. This type of amplification, as we have seen, transforms the structure of the moment of crisis. Unlike the concentrated climax of Latin comedy, several moments of crisis are diffused through the play. Neither Shakespeare nor Jonson writes in the classical tradition of the well-made play. In Shakespeare, however, "even when the climactic 
moments are diffuse, they tend to assume a reactive pattern" in that all the power of previous crises comes to focus on one particular climax. ${ }^{11}$ Jonson often deliberately disperses such intensity. Compared to Shakespeare, Jonsonian comedy is far more extensive in its mode; to put it more simply, its action is more multiple and episodic. Jonson tends to introduce new characters and new actions more freely than Shakespeare. Like Jonson, Shakespeare plots an irregular action in that scenes from different locales, social settings, and dimensions are included in one play; nevertheless, in Shakespeare there is a definite sense of narrative propulsion from the moment of precipitation of action to its recognizably narrative resolution. The action of Jonson's plays, on the other hand, bursts, subsides, meanders; given the multiplicity and autonomy of the actions, this is the most appropriate rhythm. Obviously, a structure based on the principles of causality and organic, temporal connections where minor segments of action serve merely as building blocks for the climactic moments of the play would prove ineffective in plays like Every Man Out, Cynthia's Revels, and Bartholomew Fair. Preferring episodic "copiousness," Jonson chose instead a spatial, rhythmically organized structure based on juxtaposition where the unity is provided through evident, but not organically connected, relations.

\section{Valparaiso University}

\section{Notes}

1 This is not to deny that the self-conscious Jonson had announced a dramatic programme wherein he declared his opposition to the unclassical excesses of his contemporaries. $\mathrm{He}$ never did take the liberties with time he first condemned in the prologue to Every Man In His Humour, and in the Choruses to The Magnetic Lady, he defends the structure of his play by referring to classical principles. But surely, even as we respect Johnson's statement of intentions, we can go beyond them in our understanding of his work, especially since he did not commit himself to the kind of classicism he was later identified with. In Every Man Out, he argued against the rigid application of dead rules. "I can discerne no such necessity" (that is, to obey the laws of comic form) says Cordatus, speaking for Jonson. With the ancients, comedy changed in the hands of successive geniuses, so "we should enjoy the same license, or free power" (After the Second Sounding, 245-270). All references to the text are from Ben Jonson, ed. Charles H. Herford and Percy and Evelyn Simpson, 11 vols. (Oxford: Clarendon Press, 1925-1952).

2 Freda L. Townsend, Apologie for Bartholomew Fayre (New York: The MLA of America, 1947). It is impossible to refer to all the critics who have commented on Jonson's plot structures. I note the most significant and the more recent. For echoes of Townsend see J.A. Bryant, The Compassionate Satirist (Athens: Univ. of Georgia Press, 1972), and Lawrence L. Levin, "Replication as Dramatic Strategy in the Comedies of Ben Jonson," RenD, n.s., vol. 5 (1972). Among those who have condemned some plots for excessive complexity, even as they praise others, are Wallace Bacon, "The Magnetic Field: The Structure of Jonson's Comedies," HLQ, 19 (1956), 121-53; John J. Enck, Jonson and the Comic Truth (Madison: Univ. of Wisconsin Press, 1957); and Robert E. Knoll, Ben Jonson's Plays: An Introduction (Lincoln: Univ. of Nebraska Press, 1964). Critics who defend the plays in terms of thematic 
coherence include Ray Heffner, "Unifying Symbols in the Comedy of Ben Jonson," Ben Jonson: A Collection of Critical Essays, ed. Jonas Barish (Englewood Cliff: Prentice Hall, 1963), pp. 133-46, and G.C. Thayer, Ben Jonson: Studies in the Plays (Norman: Univ. of Oklahoma Press, 1963). The most noteworthy defenses of individual comedies are those by Una Ellis Fermor, The Jacobean Drama (London: Methuen, 1936), p. 106; Jonas Barish, "The Double Plot in Volpone," MP, 51 (1953), 83-92; Mark Anderson, "The Successful Unity of Epicoene: A Defense of Ben Jonson," SEL, 10 (1970), 349-66; and Richard Levin, "The Structure of Bartholomew Fair, " PMLA, 80 (1965), 172-77.

3 See Glynne Wickham, Early English Stages, vols. 1-2 (N.Y.: Columbia Univ. Press, 19591972); George R. Kernodle, From Art to Theatre (Chicago: Univ. of Chicago Press, 1944); Samuel Chew, The Virtues Reconciled: An Iconographic Study (Toronto: Univ. of Toronto Press, 1947); Madeline Doran, Endeavors of Art (Madison: Univ. of Wisconsin Press, 1954). Bernard Beckerman in Shakespeare at the Globe, 1599-1609 (N.Y.: Macmillan, 1962) and T.J. King, "The Stage in the Time of Shakespeare," RenD, n.s. 4 (1971), 185-98, argue strongly for an essentially placeless stage.

4 Mark Rose, Shakespearean Design (Cambridge, Mass.: Harvard Univ. Press, 1972), p. 9.

5 Of late, this avenue of exploration seems to be opening up. A recent, brief survey article by Nan Cooke Carpenter, "Shakespeare and Music: Unexplored Areas," RenD, n.s. 7 (1976), 244-55, suggests that such an approach could be successfully applied to the works of Shakespeare and his contemporaries. See also Mrs. Paula Johnson, Form and Transformation in Music and Poetry of the English Renaissance (New Haven, Conn.: Yale Univ. Press, 1972). For studies on Elizabethan music see Dorothy E. Mason, Music in Elizabethan England (Wash., D.C.: Folger Shakespeare Library, 1958); Gustave Reese, Music in the Renaissance (N.Y.: Norton and Co., 1954); and F.W. Sternfeld, ed., Music from the Middle Ages to the Renaissance (N.Y.: Praeger, 1973).

6 Though the nature and function of the discovery space have been disputed, stage historians do confirm that it existed and was sometimes used for tableaux, and therefore could have a symbolic resonance. Even if these scenes were not performed on the inner stage, some of them would be acted behind curtains to the side doors or with the use of properties in the front of the stage (as with the stocks and Ursula's booth) and still retain the suggestion of physical confinement and framing.

7 J.H. Kaplan, "Dramatic and Moral Energy in Ben Jonson's Bartholomew Fair," RenD, n.s. 3 (1970), 145.

8 For critics who have commented on Shakespeare's use of mirror scenes, see Hereward T. Price, "Mirror-Scenes in Shakespeare," Joseph Quincy Adams Memorial Studies, ed. J.G. McManaway, et. al. (Wash. D.C.: Folger Shakespeare Library, 1948), pp. 101-13; Paul J. Aldus, "Analogical Probability in Shakespeare's Plays," Shakespeare Quarterly, 6 (1955), 397-414; Maynard Mack, "The Jacobean Shakespeare," Jacobean Theatre, eds. J.R. Brown and B. Harris (N.Y.: Edward Arnold, 1960), pp. 1142. Dieter Mehl, "Emblems in English Renaissance Drama," RenD, n.s. 2 (1969), 39-57, has written on connections between emblems and Elizabethan dramatic writing. Recently, critical attention has been drawn to the analogical and emblematic quality of some scenes in Jonson. To note a few, Alvin J. Kernan's introduction to the Yale edition of Volpone; Jackson Cope's "Bartholomew Fair as Blasphemy," RenD, 8 (1965), 127-52; Lawrence Levin's "Replication as Dramatic Strategy"; and Eugene M. Waith's "Things As They Are and the World of Absolutes," in Elizabethan Theatre IV, ed. G.R. Hibbard (Conn.: Shoestring Press, 1974), pp. 106-126.

9 E.B. Partridge, "Ben Jonson: The Makings of the Dramatist," Elizabethan Theatre, eds. J.R. Brown and B. Harris (London: Edward Arnold, 1966), p. 235.

10 Richard Levin, The Multiple Plot in English Renaissance Drama (Chicago: Univ. of Chicago Press, 1971), pp. 207-208.

11 Bernard Beckerman, Dynamics of Drama: Theory and Method of Analysis (New York: Alfred A. Knopf, 1970), p. 185. 